\title{
UMA TRADUÇÃO DE $O$ CÁGADO, POEMA DE GUIMARÃES ROSA, PARA O ESPANHOL
}

\author{
A TRANSLATION OF O CÁGADO, A GUIMARÃES ROSA 'S POEM, INTO \\ SPANISH

\section{UNA TRADUCCIÓN DE O CÁGADO, POEMA DE GUIMARÃES ROSA, EN ESPAÑOL}

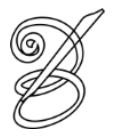 \\ Raimundo Expedito dos Santos SOUSA* \\ Faculdade do Centro Educacional Mineiro, Brasil \\ Hugo Domínguez SILVA** \\ Universita Degli Studi di Napoli L'orientale, Itália
}

Todos os clichês sobre o fundo e a forma, a prosa e a poesia, o escrito e o oral, o gênio das línguas, formam a matéria ideológica deste magma, os mitos da linguagem que alguns tomam por uma transparência.

Henri Meschonnic, Poética do traduzir.

\begin{abstract}
Resumo: O parentesco entre o português e o espanhol constitui, ao mesmo tempo, um fator que facilita e dificulta a tradução interlingual. Diferentemente da tradução entre línguas muito distintas entre si, a transferência linguística entre idiomas com relação parentética se dá mediante emprego mais recorrente das modalidades de tradução direta. Contudo, a mesma proximidade que faz o espanhol parecer mais acessível ao lusófono e o português ao hispanofalante do que outros idiomas impõe armadilhas mesmo ao tradutor profissional, sobretudo se não houver decisão apriorística quanto ao enfoque adotado. A fim de explorar os desafios da tradução literária entre línguasfonte e língua-alvo em princípio muito afins, este artigo propõe uma tradução, para o espanhol, do poema $O$ cágado, escrito pelo brasileiro João Guimarães Rosa e inserido na coletânea Magma, de publicação póstuma. Longe de arbitrária, a seleção de Magma como objeto de análise se justifica por ser um livro de poemas pouco estudado pela crítica do escritor mineiro - mais conhecido por sua produção narrativa -, coadunar influências modernistas com o estilo propriamente rosiano e, assim, antecipar temas retomados em obras posteriores, como Sagarana e Grande Sertão: Veredas. Ao levarmos em consideração as peculiaridades do poema, bem como da escrita rosiana tout court, optamos por um exercício tradutório cuja primazia repousa no elemento rítmico. Essa perspectiva teórica tem como base autores especializados na tradução poética, sobretudo Henri Meschonic, que retoma os estudos dos seus antecessores, como Ezra Pound. Além de apresentarmos uma tradução inédita, realizamos um exercício metatextual de reflexão sobre os principais desafios enfrentados no processo de transladação. A prática da tradução, seguida de reflexão sobre a experiência mesma da recriação, restou evidente que a tradução do português para o espanhol, sobretudo de um texto do gênero poético, apresenta fatores sintáticos, semânticos e pragmáticos que facilitam o processo tradutório e outros tantos que o dificultam.
\end{abstract}

Palavras-chave: João Guimarães Rosa. Magma. O cágado. Tradução. Português/Espanhol.

Abstract: The relationship between Portuguese and Spanish is at once a factor that facilitates and hinders interlingual translation. Unlike the translation between languages that are very different from one another, the linguistic transfer between languages with parenthetical relationship occurs through more recurrent use of direct 
translation modalities. However, the same proximity that makes the Spanish seem more accessible to the Portuguese-speaking people and Portuguese to the Spanish-speaking people than other languages imposes traps even to the professional translator, especially if there is no aprioristic decision regarding the approach taken. In order to explore the challenges of literary translation between source languages and target languages in principle closely related, this paper proposes a translation, into Spanish, of the poem $\mathrm{O}$ cágado, written by the Brazilian João Guimarães Rosa and inserted in the collection Magma, of posthumous publication. Far from arbitrary, the selection of Magma as an object of analysis is justified because it is a book of poems scarcely studied by the critics of this writer from Minas Gerais - better known for his narrative production -, besides to coordinate modernist influences with the style properly Rosian and, thus, to anticipate subjects resumed in later works, such as Sagarana and Grande Sertão: Veredas. Considering the peculiarities of the poem, as well as the Rosian writing tout court, we opted for a translation exercise whose primacy rests on the rhythmic element. This theoretical perspective is based on authors specializing in poetic translation, especially Henri Meschonic, who takes up the studies of his predecessors, such as Ezra Pound. In addition to presenting an unpublished translation, we carried out a metatextual exercise of reflection on the main challenges faced in the translation process. The practice of translation, followed by reflection about the very experience of re-creation, showed that the translation from Portuguese into Spanish, especially from a text of the poetic genre, presents syntactic, semantic and pragmatic factors that facilitate the process of translation and others that make it difficult.

Keywords: João Guimarães Rosa. Magma. O cágado. Translation. Portuguese/Spanish.

Resumen: La relación entre el portugués y el español constituye, simultáneamente, un factor que facilita y dificulta la traducción interlingual. A diferencia de la traducción entre lenguas de distinta procedencia, la transferencia lingüística entre idiomas con relación de parentesco se produce a través de un uso más recurrente de las modalidades de traducción directa. No obstante, la misma proximidad que hace que el español parezca más accesible al hablante lusófono y el portugués al hispanohablante, frente a otras lenguas, impone trampas incluso para el traductor profesional, especialmente si no hay una decisión apriorística con respecto al enfoque adoptado. Con el fin de explorar los desafíos de la traducción literaria entre lengua origen y la lengua meta, este artículo propone una traducción al español del poema $\mathrm{O}$ cágado escrito por el brasileño João Guimarães Rosa e insertado en el libro Magma, de publicación póstuma. Lejos de ser arbitraria, la selección de Magma como objeto de análisis se justifica porque es un libro de poemas poco estudiado por la crítica del escritor de Minas Gerais, mejor conocido por su producción narrativa, por combinar las influencias modernistas con el estilo propio de Rosa y por anticipar los temas retomados en trabajos posteriores, como Sagarana y Grande sertão: veredas. Cuando tomamos en cuenta las peculiaridades del poema, así como la escritura de Rosa tout court, optamos por un ejercicio de traducción cuya primacía se fundamenta en el elemento rítmico. Esta perspectiva teórica se basa en autores especializados en la traducción poética, en particular Henri Meschonic, que retoma los estudios de sus predecesores, como Ezra Pound. Además de presentar una traducción inédita, llevamos a cabo un ejercicio metatextual de reflexión sobre los principales desafíos enfrentados en el proceso de traducción. La práctica de la traducción, seguida de una reflexión sobre la experiencia misma de la recreación, hizo evidente que la traducción del portugués al español, aún más en un texto del género poético, presenta factores sintácticos, semánticos y pragmáticos que facilitan el proceso de traducción y otros que lo dificultan.

Palabras clave: João Guimarães Rosa. Magma. O cágado. Traducción. Portugués/Español.

RECEBIDO EM: 30/03/2019

ACEITO EM: 12/08/2019

PUBLICADO EM: 10/2019

SOUSA, Raimundo Expedito dos Santos; SILVA, Hugo Domínguez. Uma tradução de O cágado, poema de Guimarães Rosa, para o espanhol. Belas Infiéis, Brasília, v. 8, n. 4, p. 175-191, 2019. 


\section{Introdução: o português, o espanhol e os desafios tradutoriais}

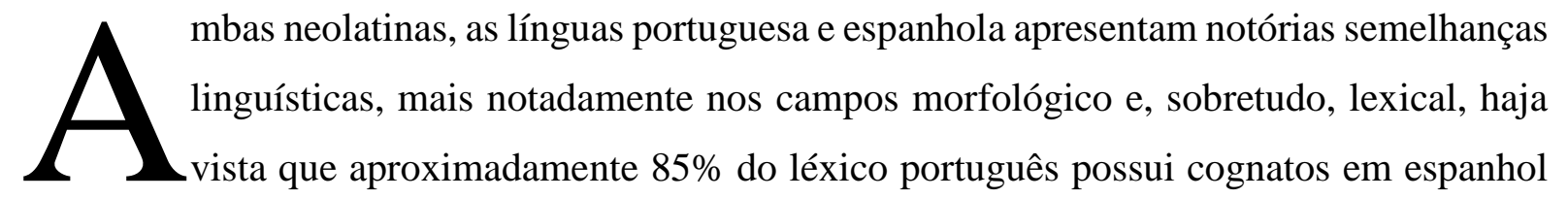

(ULSH, 1971). Esse vínculo parentético favorece, em tese, práticas como a tradução, pois, aparentemente, não demanda recursos transferenciais complexos. Vinay e Darbelnet (1958), em trabalho seminal para as teorias da tradução, assinalam que a chamada tradução literal (palavra por palavra) é tanto mais exequível quanto mais próximo for o grau de parentesco entre dois idiomas. Se bem que, no campo sintático, as línguas portuguesa e espanhola também sigam estruturação similar, aqui reside o principal ponto de inflexão entre ambas, uma vez que se diferem, por exemplo, quanto à colocação pronominal, como em "vou me banhar", cujo correspondente em espanhol, "me voy a bañar", emprega uma próclise que, no português formal, deveria dar lugar à ênclise.

O aparente benefício da proximidade tipológica entre as línguas é minorado, sobretudo, no âmbito da tradução literária, dadas as especificidades estilísticas do texto literário, evidenciada no emprego de recursos expressivos como as figuras de linguagem e suas subdivisões em figuras de palavras, de construção, de pensamento e de som. Some-se a isso o reflexo linguístico das diferenças culturais entre o português e o espanhol matriciais (da Península Ibérica) e suas distintas acomodações nas ex-colônias resultar em idiossincrasias que dificultam a tradução interlingual, a fortiori na literatura. A fim de explorar os desafios da transferência linguística em traduções literárias entre línguas-fonte e língua-alvo em princípio muito afins, este artigo propõe uma tradução, para o espanhol, do poema $O$ cágado, escrito pelo brasileiro João Guimarães Rosa e inserido na coletânea Magma, de publicação póstuma. Além de apresentarmos uma proposta de tradução inédita, realizaremos um exercício metatextual de reflexão sobre os principais desafios enfrentados no processo de transladação.

\section{Magma e a poesia modernista}

Etimologicamente, o termo "poesia", do grego poiésis, significa "criação" e implica uma gama de usos figurativos que podem, inclusive, relacionar o poético a algo de todo heteróclito ao seu significado original, até atingir o patamar kafkiano. Os elementos tradicionalmente associados à poesia e que já foram, no passado, mais ou menos obrigatórios segundo paradigmas estéticos vigentes em determinados contextos - vide a métrica e a rima são, hoje, completamente prescindíveis (GARCÍA DE LA BANDA, 1993). Esse é, a propósito, 
um apanágio estruturante de Magma, de João Guimarães Rosa, livro de poesia quase tão narrativo quanto Grande Sertão: Veredas, tal que se deve lê-lo, a nosso ver, como artefato antes narrativo do que poético. Contudo, a imputação de caráter prosaico a uma obra não implica desconsiderar seu ritmo poético; ao contrário, talvez resida, nessa idiossincrasia composicional, sua principal relevância literária e seu interesse como objeto de investigação. Nesse sentido, valemo-nos da teoria defendida pelo francês Henri Meschonnic, que, ao proceder à tradução da Bíblia, notou nas Sagradas Escrituras acentuada musicalidade estratégica e por isso se valeu dos conceitos de ritmo e historicidade de Humboldt e Benveniste (MESCHONNIC, 2010). No prisma de Meschonnic, o ritmo constitui “a organização e a própria operação do sentido no discurso", pois "o objetivo da tradução não é mais o sentido, mas bem mais que o sentido, e que o inclui: o modo de significar" (MESCHONNIC, 2010, p. xiii). Essa técnica aplicada evidencia que "o ritmo, como dado imediato e fundamental da linguagem, e não mais em sua limitação formal e tradicional, renova a tradução e constitui um critério para a historicidade das traduções, seu valor. Sua poética e sua poeticidade” (MESCHONNIC, 2010, p. 41).

Precisamente porque Magma se inscreve no panorama literário do seu tempo, há, no 178 livro, aproximação com a poesia modernista da década de 1920, que manifesta límpido interesse pela realidade nacional. Prova disso reside na incorporação de elementos prosaicos, acompanhada de exploração da paródia ou de meditação intimista, tal que a temática metafísica ou mística convive com a recriação de aspectos da vida brasileira. Graças a esse trabalho, Guimarães Rosa foi laureado com o Primeiro Prêmio de Poesia da Academia Brasileira de Letras, em 1937. Porém, sempre considerou a coletânea bastante aquém da potência expressiva da sua produção posterior, vide sua constrangida aceitação do filho bastardo no discurso de agradecimento pelo prêmio: "o Magma, aqui dentro, reagiu, tomou vida própria, individualizou-se, liberou-se do meu desamor e se fez criatura autônoma, com quem talvez eu já não esteja muito de acordo, mas a quem a vossa consagração me força a respeitar" (ROSA, 1997, p. 5). Uma vez que o escritor mineiro não quis publicá-la em vida, a obra só seria descoberta 54 anos depois, por Hygia Therezinha Calmon Ferreira, na sua tese doutoral João Guimarães Rosa: as sete sereias do longe, apresentada na universidade de São Paulo, e teríamos de esperar até 1997 para vê-la publicada pela primeira vez (LEONEL, 2000).

Leonel, em Magma e gênese da obra, parafraseia Gabriel García Márquez ao afirmar que "para compreender a voz da maturidade, é preciso vasculhar as dicções que ela assumiu ao longo da juventude” (LEONEL, 2000, p. 16). Nossa perspectiva não é exatamente essa, mas de que uma obra como Magma vale por si mesma devido às suas particularidades intrínsecas, do 
mesmo modo que Grande Sertão: Veredas pode ser interpretado como um poema ou um conjunto de contos. Quanto à feição estilística do livro, os versos são livres, a rima é ausente ou irregular e o agramaticalismo, dissonância entre a sintaxe e a linha do verso, é comum. Embora os temas sejam numerosos e convergentes, Leonel (2000) os distribui em sete grandes grupos: animais, natureza, vida no campo, manifestações culturais negras e indígenas, mitos e crendices, amor e proposições filosóficas.

\section{A traduzibilidade da poesia}

A tradução literária tem sido, há muito, tema de controvérsias entre escritores, tradutores e estudiosos da tradução. Por um lado, há quem argumente que essa modalidade de tradução é impraticável, uma vez que jamais atingirá o nível do texto-fonte. Uma obra literária deveria ser apreciada, portanto, no idioma original em que foi escrita, sob pena de prejuízo à fruição estética devido à não captação, pelo leitor, de minudências que se perdem na tradução. Alinhado a essa perspectiva, o poeta estadunidense Robert Frost sinalizou a impossibilidade da tradução poética ao considerar que "a poesia é aquilo que desaparece quando é traduzida", ponto de vista compartilhado por Victor Hugo, Voltaire e Vladimir Nabokov (GARCÍA DE LA BANDA, 1993, p. 119). Esse axioma se nos afigura tão contraditório que Manuel Bandeira endossava a não traduzibilidade da poesia, mas foi, ele próprio, um prolífico tradutor de poetas estrangeiros para o português (JUNQUEIRA, 2012). Por outro lado, nas fileiras dos que consideram possível a tradução da poesia - e aos quais nos filiamos -, estão Roman Jakobson, Paul Valéry e Ezra Pound. Para este último, existem três tipos de poesia: a melopeia música das palavras; a fanopeia, matéria visual; e a logopeia, elemento intelectual (GARCÍA DE LA BANDA, 1993). Os muitos que advogam em favor da traduzibilidade do texto literário, sob o ponto de vista tanto da ampliação da acessibilidade da obra para públicos que de outro modo seriam incapazes de ler um texto estrangeiro, quanto da própria finura literária do texto-alvo, ressalvam que, inevitavelmente, perde-se algo do significado pretendido pelo autor do texto-fonte, bem como da moldura em que tal significado é formatado. A propósito desse cunho subtrativo, é preciso ponderar que a tradução não aspira, por evidente, à cópia especular do texto matricial, visto que sua condição derivativa constitui antes uma recriação do que uma tentativa mimética:

\footnotetext{
os inimigos da tradução poética devem lembrar-se de que, diferentemente de um leitor que se põe a sonhar com o eventual sentido de uma palavra, o tradutor não opera no plano da ortonímia, e sim no da sinonímia, buscando menos a nomeação absoluta do que a nomeação aproximativa, razão pela qual o seu estatuto é não o de criador, mas antes o de recriador (JUNQUEIRA, 2012, p. 12).
} 
Afora as divergências entre partidários de uma ou de outra posição, é inconteste que a tradução literária possui algumas propriedades que a distinguem de outros tipos de tradução. Talvez a diferença mais substancial resida no fato de que, nessa modalidade tradutória, a forma como se transmite o texto original é tão relevante quanto o conteúdo transmitido. Portanto, o processo de tradução literária difere frontalmente de formas mais mecânicas de tradução porque elementos estéticos devem ser considerados enquanto partes constitutivas de textos timbrados pela complementaridade entre forma e conteúdo. Disso decorre, pois, outro predicado da tradução literária, qual seja, a liberdade criativa do tradutor para adequar à língua-fonte artifícios estilísticos que se perderiam numa tradução ad litteris et verbis. Em contraposição, essa liberdade exige do tradutor um profundo conhecimento das características do autor por ele traduzido, como é o caso de Guimarães Rosa, cujo uso peculiar da linguagem impõe dificuldades hermenêuticas até mesmo ao leitor médio brasileiro. Essa diligência contradiz o axioma da inferioridade constitutiva da tradução em face do texto primevo, uma vez que

a tradução exige esforço mais extenso e intenso do que a criação propriamente dita, sobretudo quando se trata do traslado de textos poéticos, nos quais [...] resta ainda ao tradutor o desafio de interpretar o pensamento do autor, sem falar nos problemas de atmosfera poética, que é necessário recriar em outra língua, e, intimamente vinculado a esses, o da escolha do vocabulário, pois há palavras que podem suscitar uma sugestão poética em determinada língua e em outras não, caso se trate de uma tradução literal. É nesse resgate de equivalências que reside o mérito de qualquer tradução. E pode-se dizer até que a maior virtude de qualquer espécie de tradução é não dar nunca a impressão de que o foi (JUNQUEIRA, 2012, p. 10).

Ao recuperar a etimologia do verbo latino traducĕre (literalmente, transportar de um lugar para outro), Meschonnic representa o tradutor como um barqueiro para argumentar que mais importante do que transportar é o estado no qual o que foi conduzido chega ao seu destino. Esse empreendimento tradutório consiste na aplicação de uma nova técnica na literatura poética brasileira, em um livro subestimado pelo próprio Guimarães Rosa e, talvez por isso, negligenciado pela crítica. Nosso interesse repousa na estreita ligação entre teoria e prática, visto que "só há teoria através da prática" e que "a tradução é primeiro uma questão empírica" (MESCHONNIC, 2010, p. 42). Magma, livro de incalculável interesse literário, dá a ver que poesia e romance não estão tão afastados. Conforme evidenciaremos, sua tradução é um exercício interlingual que evidencia a flexibilidade da linguagem humana e do signo linguístico. 


\section{Tradução do poema $O$ cágado}

Apresentamos, no que se segue, a transcrição do poema $O$ cágado, enfeixado na coletânea Magma e aqui emparelhado, verso a verso, com nossa proposta de tradução:

O cágado

Numa dobra da serra

há um minadouro,

uma bica,

e um poço azul.

E ali, na água redonda, pequenina e fria, mora um cágado escafandrista,

filósofo pessimista,

que tem a mania da perseguição.

Quando o sol bate de cheio,

ele traz para fora a cuia emborcada,

e se aquece, aberto, em cima da laje,

chato, cascudo e feio.

Mas, se alguém pisa perto,

ele escorrega e pula, na água mansa

que explode e respinga.

Leva bom tempo

para assomar o focinho

de periscópio.

Mas, se é falso o alarma,

lá vem aflorando, levemente, à tona,

a concha remendada com fiapos de limo.

Depois, mais afoito,

o prudente réptil

passeia o dorso, convexo e abaulado,

como um "U-18"

da base de Kiel.
El galápago

En un rincón de la sierra

hay un arroyo,

una pila,

y una poza azul.

$Y$ allí, en la charca redonda, pequeña y fría,

vive un galápago escafandrista,

filósofo pesimista,

que tiene la manía de la persecución.

Cuando el sol pega de lleno,

lleva afuera su jícara volcada,

y se calienta, abierto, sobre la losa,

aburrido, cascarudo y feo.

Pero, si alguien está al acecho,

se escurre y salta, en el agua mansa

que explota y salpica.

Le lleva un buen tiempo

asomar el hocico

de periscopio.

Pero, si es falsa la alarma,

ahí viene aflorando, levemente, flota

la concha remendada con fibras de limo.

Después, más lanzado,

el prudente reptil

pasea el dorso, convexo y abombado,

como un " $U-18$ "

de la base de Kiel. 
E o caipira guarda a vida do monstrengo

(Ai! meus pecados todos!...),

se o matarem, o olho d'água se evapora

(Ai! minha felicidade pequenina!...)

E o cágado, lento e pré-diluviano,

na cacimba da grota, espera outro Dilúvio...
Y el lugareño vela por la vida del bichejo

( $A$ Ay, por todos mis pecados!),

si lo matan, el manantial se evapora

( Ay, por mi felicidad diminuta...!)

Y el galápago, lento, antediluviano,

en la guarida de la gruta, espera otro Diluvio...

\section{Interpretação e análise de $O$ cágado}

O cágado é um bom exemplo de reflexão filosófica e metafísica (logopeia) sob uma auréola, na forma visual, de falsa-infantilidade (fanopeia), pois lembra um conto maravilhoso de tradição europeia (Perrault, Irmãos Grimm e Andersen) ou uma arquetípica fábula da literatura greco-romana (Esopo, Fedro). De início, apresenta o espaço com uma série de enumerações, a partir da forte presença do artigo indefinido. O cágado é representado com traços humanoides e marcado pelo desalento e pelo fastio existencial ("filósofo pessimista", “chato", “espera outro Dilúvio"). O lugar, ainda que inexato, é facilmente identificável como o sertão mineiro graças a elementos como "minadouro" e "caipira", de maneira que a imagem do cágado dentro da carapaça pode ser vista como transfiguração metafórica do homem sertanejo do interior de Minas Gerais. Encontramos, pois, em Magma, o mesmo debate que Antônio Cândido expôs a respeito de Grande Sertão: Veredas ao indagar se a obra pretende constituir uma figuração do Brasil ou do mundo em geral. Nessa ótica, o cágado não seria uma representação apenas do mineiro, mas do ser humano universal:

\footnotetext{
a experiência documentária de Guimarães Rosa, a observação da vida sertaneja, a paixão pela coisa e pelo nome da coisa, a capacidade de entrar na psicologia do rústico, - tudo se transformou em significado universal graças à invenção, que subtrai o livro à matriz regional para fazê-lo exprimir os grandes lugares comuns, sem os quais a arte não sobrevive: dor, júbilo, ódio, amor, morte, — para cuja órbita nos arrasta a cada instante, mostrando que o pitoresco é acessório e que na verdade o Sertão é o Mundo (CANDIDO, 2002, p. 122).
}

O poema apresenta numerosos contrastes, como o jogo de alternância entre calmaria e explosão (LEONEL, 2000): a água do "minadouro" sai à superfície, enquanto a água da "bica" cai; o cágado é "afoito", porém "prudente"; ele é um medroso que "assoma o periscópio", mas tem o dorso como um "U-18" (submarino alemão ativo na Primeira Guerra). Esse eco da guerra demonstra que Guimarães Rosa não ficou indiferente ao contexto histórico global ao escrever Magma - recorde-se que o livro foi premiado em 1937 e a Segunda Guerra não eclodiria antes de 1939. O porto de Kiel (a $100 \mathrm{~km}$ de Hamburgo) foi um famoso fabricante de u-boots 
(submarinos nomeados com letra "U" seguida de um número) e um local onde os marinheiros da Kaiserliche Marine protagonizaram rebelião em outubro de 1918. Leonel (2000) sustenta essa relação de Rosa com a guerra ao comparar a forma física de alguns animais de Magma com o formato de um tanque - vide o poema $O$ caranguejo - e estabelece paralelismo entre a carapaça e um tanque de guerra.

No poema $O$ cágado, Guimarães Rosa tematiza a existência em si mesma e, para tanto, (con)funde animal, humano e espaço (um magma), porque se o cágado desaparece a água se desvanece com ele ("se o matarem, o olho d'água se evapora"). Numa análise mais detida, pode-se notar que o tema de fundo consiste no sofrimento do taedium vitae, mas também na razão intrínseca da vida: sem o viver o mundo não existiria. Com estrutura bem marcada, o poema possui introdução (apresentação do lugar e da personagem, que corresponderia à primeira estrofe); uma ação nas duas estrofes do meio, que, na realidade, é uma não-ação, precisamente para criticar a passividade do cágado ("Mas, se alguém pisa perto, ele escorrega e pula"); e uma estrofe final que resume a associação da história - uma moral que se pode relacionar com a filosofia de Plotino, segundo a qual o ser divino é indivisível (cf. HARLAND, 2004). No plano rítmico (melopeia), há criação de musicalidade mediante assonâncias: "escafandrista" - "pessimista"; "fria" - "mania"; "cheio" - "feio" - "perto"; "focinho" "limo" - "dezoito".

\section{Comentários sobre a tradução, as dificuldades e as soluções adotadas}

Se, conforme já afirmamos neste artigo, a tradução literária chancela o élan criativo do tradutor porque se dá, diferentemente de outras modalidades tradutórias, para além do patamar conteudístico, essa liberdade lhe impõe responsabilidades, dentre as quais a tomada de decisões quanto à forma mais adequada de traduzir todo o texto literário, determinada passagem ou mesmo uma palavra específica. Essas escolhas, não raro dificultosas, acentuam-se, sobretudo, quando da tradução do gênero poético, em face da constelação de recursos peculiares ao gênero:

a tradução de poesia é também, sob certos aspectos, um proveitoso exercício de crítica paralela, pois a todo instante esse homo ludens em que consiste o tradutor - ou o recriador [...] - está diante do complexo e prismático problema da escolha, dessa escolha que se processa no plano do significado e do significante, o que envolve [...] opções semânticas, fonéticas, morfológicas, sintáticas, prosódicas, rítmicas, métricas, rímicas, estróficas - enfim, um espectro ambíguo e infinito constituído pelas chamadas figuras de linguagem (JUNQUEIRA, 2012, p. 13). 
Frente à necessidade de escolha, optamos por empregar na tradução de $O$ cágado o primado do ritmo, uma vez que contempla a peculiaridade rítmica do poema. "Mais do que o sentido, e mesmo aí onde o sentido das palavras aparentemente não é modificado, o ritmo transforma o modo de significar", argumenta Meschonnic, que complementa: "o que é dito muda completamente, conforme levamos em conta este ritmo ou não, a significância ou não" (MESCHONNIC, 2010, p. 46). O caráter oral da poética rosiana faz com que o sentido das palavras perca importância em relação ao ritmo, tanto que se rompe com o que Meschonnic denomina "dogma do dualismo do sentido saussuriano":

\begin{abstract}
aos maus entendedores dogmáticos do dualismo, que continuam a restringir os problemas da tradução a uma concepção do sentido que a significância devolve a todo momento à sua pobreza teórica, cabe contrapor que o valor do sentido de Saussure, no discurso só flui por conta do ritmo. O ritmo mostra que o primado caduco do sentido se faz substituir por uma noção mais possante, [...] já que ela pode se realizar no imperceptível, por seus efeitos de escuta e de tradução: o modo de significar. No que a aventura da tradução e a do ritmo são solidárias (MESCHONNIC, 2010, p. 56).
\end{abstract}

Para a tradução do título, levamos em conta a magnum opus de Guimarães Rosa, Grande 184 Sertão: Veredas, traduzida para o espanhol, entre outros, pela Fundação Editorial El perro y la rana, em 2008. Consideramos esse trabalho tradutório um rico manancial para criarmos uma base de dados terminológica de que nos serviríamos na tradução do poema: "E é rio cheio de bichos cágados. Se olhava a lado, se via um vivente desses - em cima de pedra, quentando sol, ou nadando descoberto, exato"1 (ROSA, 1994, p. 139). Na versão espanhola encontramos a seguinte tradução: y es río lleno de bichos galápagos. Se miraba a un lado, se veía uno de aquellos vivientes: encima de una piedra, calentando sol, o nadando descubierto, exacto (ROSA, 2008, p. 97). Optamos, então, por traduzir "cágado" como galápago e descartar outras palavras do tipo quelonio (nome genérico da espécie) ou tortuga (que não conserva a rima em $-o)$.

Em seguida, expomos alguns dos desafios que enfrentamos em termos fonéticos, morfológicos, sintáticos, pragmáticos e extralinguísticos (NORD, 2012) e as soluções encontradas a partir das propostas de Hurtado Albir (2011). No primeiro parágrafo, a palavra "minadouro" apresenta dificuldade tradutória por não ter um cognato em espanhol. Talvez Guimarães Rosa a tenha usado em referência à exploração aurífera em Minas Gerais, mas a palavra, em si, refere-se à água que sai da terra em forma de gêiser. A partir dessa definição, encontramos outro vocábulo interessante: "córrego". A palavra "minadouro" não aparece em Grande Sertão: Veredas, mas "córrego" é tão frequente que já consta na primeira página do 
livro: "NONADA. TIROS QUE O SENHOR ouviu foram de briga de homem não, Deus esteja. Alvejei mira em árvores no quintal, no baixo do córrego" (ROSA, 1994, p. 3).

Visto que a tradução espanhola de "córrego" é corriente ou arroyo, escolhemos a última para conservar a aliteração em vibrante (dobra - serra - minadouro; rincón - sierra - arroyo). A palavra "bica" também é de difícil tradução em espanhol, porque só temos o genérico fuente, que, porém, não tem rima em - $a$, como "bica". A palavra pila, com sentido de abrevadero, é a única que mantém a rima e se inscreve no campo semântico campesino, além de nos remeter à ação humana como modificadora da canalização da água. "Poço azul" é, para o mineiro, sinônimo de "charco" ou "lagoinha". Em espanhol, pozo é quase sempre referido ao "poço" como buraco de onde se extrai água potável. No entanto, poza é um sinónimo de charca e por isso resolvemos trocar o gênero. No último parágrafo, encontramos "olho d'água" e então aproveitamos a palavra para recuperar o sentido de naciente, que se perdera na tradução de "bica" como pila, porque manantial tem o sentido de lugar que produz água. Uma última precisão foi traduzir "água redonda" como charca redonda. Essa decisão mirou evitar a ambiguidade da aplicação de um adjetivo concreto a um conceito abstrato, algo que em português é possível (“olho d'água"), mas que em espanhol resulta estranho por falta de recorrência dessa metáfora nos corpora literários ${ }^{2}$.

No segundo parágrafo, fazemos o mesmo que com "cágado" e procuramos a palavra "cuia" em Grande Sertão: Veredas: "ele nu nuelo, mesmo em junho frio, lavram o corpinho dele na peia e na taca, depois limpam a pele do sangue, com cuia de salmoura" (ROSA, 1994, p. 11). A tradução na versão espanhola é a seguinte: desnudo desnudito, hasta en junio frío, le señalan el cuerpo con la maniota y la correa, después le limpian la piel de sangre, con jícaras de salmuera (ROSA, 2008, p. 18). Escolhemos, então, jícara como tradução de "cuia". Outro problema no plano lexical consiste na palavra "cascudo". Em espanhol, cascudo é um animal que possui muito casco nos pés. Porém, temos a palavra cascarudo ${ }^{3}$ (que tiene gruesa la cáscara), que, aliás, acomoda-se perfeitamente ao poema porque cascarudo lembra uma fusão entre testarudo e cascarrabias (palavras afinadas com a pessoalidade do cágado). Poderíamos também comentar uma mesma lógica rítmica do som oclusivo velar surdo [k] nas palavras escolhidas na tradução, porque, como Meshonnic salienta, "a poesia e o ritmo estão de fato incluídos na métrica" e devemos entender o texto "primeiro como métrica, depois como uma retórica" (MESCHONNIC, 2010, p. 44). Nesse sentido, podemos relacionar cascarudo com "escafandrista", "convexo" (qualidades físicas do cágado); hocico, periscopio (partes anatômicas metafóricas do cágado, pois não possui "focinho", como os porcos, nem periscópio, 
como os submarinos); escurre, salpica, volcada, se calienta (verbos que se referem às consequências de uma ação); Kiel (o nome de uma cidade alemã); rincón, charca (nome de lugares referidos ao "cágado"); jícara, concha (sinônimos de "carapaça"). Sem dúvida, o protagonista desse poema será, na tradução, esse som, para lembrar que, no original, o título em português também levava esse $[\mathrm{k}]$, que se perdeu. Trata-se de uma estratégia de compensação e criação de musicalidade e ritmo que mostra o interesse do tradutor em ir além da mera transferência de palavras da língua-fonte para a língua-alvo. Leonel faz notar essa importância do som velar, até por parte do escritor: “o c[k]ágado associa som e significado na descrição do animal e se reveste de simplicidade" (LEONEL, 2000, p. 78). A crítica literária ainda explica que a palavra foi emendada:

no título e nos demais momentos em que o nome do animal é repetido na composição, as emendas indicam a substituição da letra $c$ pela letra $k$. Certamente o escritor supôs um valor nessa substituição, que não é mantida e sobre a qual nada se informa (LEONEL, 2000, p. 26).

A edição da Nova Fronteira optou por manter "cágado" sem a letra $k$, mas o poema está acompanhado de um desenho de Poty, que franqueia ao leitor a identificação do cágado com a letra $k$ (graças ao guarda-chuva e ao buriti, dois símbolos de Minas Gerais). Outro fenômeno dessa mesma estrofe é a rima entre "cheio" - "feio" - "perto", um problema de tipo pragmático. No espanhol, existe lleno e feo, mas, para "perto", só existe a palavra cerca. Por isso, fazemos uma pequena modificação: traduzimos "se alguém pisa perto" por si alguien está al acecho, de sorte que conservamos o mesmo sentido (o de alguém perto, aproximando-se), mas com uma rima em -eo. Ainda no plano fonético, um fenômeno de aliteração fônica pode ser considerado em losa - mansa, criado pelo tradutor, já que não existe no original (laje - mansa), mas é motivado pela perda de outra aliteração que não pode ser mantida: "escorrega" - "respinga". A estratégia, portanto, é a substituição. Na terceira estrofe, ocorre o mesmo fenômeno com o som fricativo: "afoito" - "fiapo". Uma vez que a tradução de "fiapo" seria hebras e pelusa, procuramos uma palavra, nesse mesmo sentido, com o som fricativo e encontramos fibra. É curioso como Guimarães Rosa utiliza um recurso metafórico ao comparar a carapaça a um tecido remendado com a sujeira da lama nas bordas. No caso de "afoito", adotamos uma estratégia de dupla função: afastamos sua relação fônica com "falso" e "fiapo" e o traduzimos como lanzado, ligamo-lo com abombado pela rima em -ado e com limo por terem em comum as letras $l, m$ e $o$. Em contrapartida, ligamos fibras a falsa e flota. Dessa forma, fazemos com que a palavra "afoito" adquira uma nova função, que tem coerência dentro do texto, e assim 
conservamos o ritmo, pois, como vimos, Meschonnic contesta a separação saussuriana: “oralidade neutraliza a oposição dual própria ao reino do signo, entre o escrito e o falado. Leva, pois, a distinguir o oral do falado, o oral como primado do ritmo no discurso" (MESCHONNIC, 2010 , p. 44). Priorizamos, com isso, o ritmo do oral, o que pode ser ilustrado no seguinte esquema: criamos uma dupla aliteração a partir de dois termos que não rimavam no original: "à tona" (flota) e "abaulado" (abombado).

Figura 1

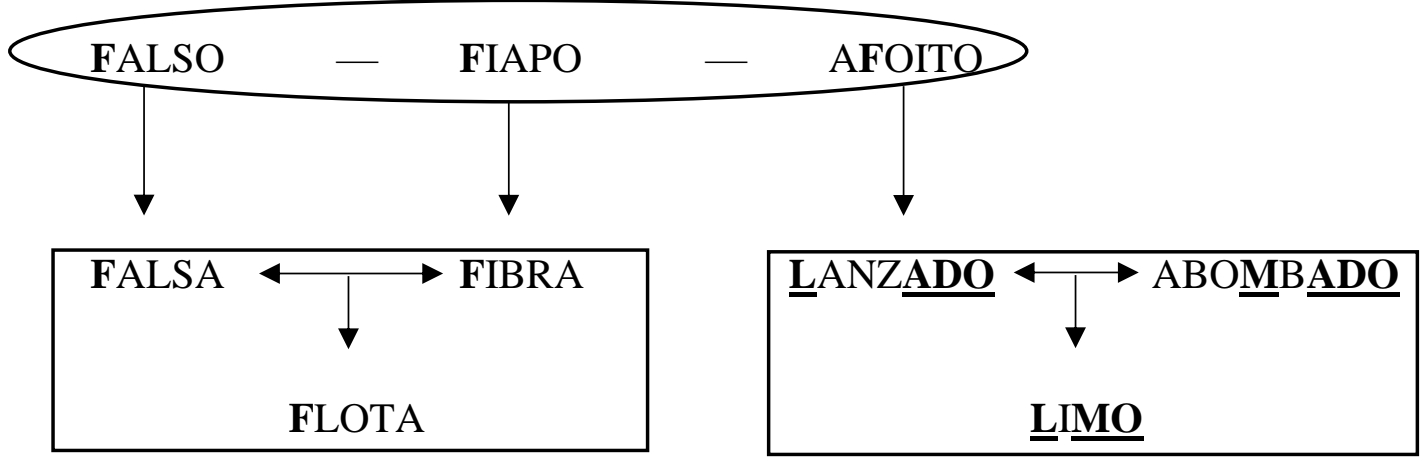

Elaboração: os autores

O quarto e último parágrafo apresenta dificuldades que são, primordialmente, de tipo sintático. Referimo-nos aos dois versos que são parte recriada do discurso pronunciado pelo chamado "caipira": "ai! meus pecados todos!...", "Ai! minha felicidade pequenina!..." sentenças que expressam a infelicidade do interlocutor e que são essenciais como conclusão e compreensão final do sentido do poema. Na tradução, adicionamos a preposição "por", sublinhando o caráter de lamento da pessoa que fala (em espanhol, essa é uma estrutura mais frequente, haja vista que "meu Deus!” pode ser traduzido como “ipor Dios!") e mudamos a ordem dos elementos para construir um verso mais natural. Outra construção é a que podemos chamar de "superlativo hebraico": "na cacimba da grota". Como as palavras "cacimba" e "grota" são parecidas no sentido de "lugar da montanha com um depósito de água onde podem se abrigar os animais", decidimos traduzir cacimba por "guarida", pois, além de ter o significado de "toca" e "cova", também tem similitude fonética com a palavra "gruta", intensificando o valor visual. Uma última dificuldade interessante, presente tanto na primeira estrofe quanto na última, é a da palavra "pequenina". Em Grande Sertão: Veredas aparece duas vezes: 
Quadro 1

\begin{tabular}{|c|c|}
\hline Texto original & Texto traduzido \\
\hline $\begin{array}{l}\text { "Eu gosto de matar..." - uma ocasião ele } \\
\text { pequenino me disse. (ROSA, 1994, p. } \\
\text { 11) }\end{array}$ & $\begin{array}{l}\text { "Me gusta matar...", me dijo en una } \\
\text { ocasión, siendo pequeñito. (ROSA, 2008, } \\
\text { p. 18) }\end{array}$ \\
\hline $\begin{array}{l}\text { Esses Gerais em serras planas, beleza por } \\
\text { ser tudo tão grande, repondo a gente } \\
\text { pequenino. (ROSA, } 1994, \text { p. } 445 \text { ) }\end{array}$ & $\begin{array}{l}\text { Aquellos Generales de sierras planas, una } \\
\text { belleza por ser todo tan grande, dejándote } \\
\text { chiquito. (ROSA, } 2008 \text {, p. } 280 \text { ) }\end{array}$ \\
\hline
\end{tabular}

Fonte: Rosa, 1994, 2008.

A nosso ver, a tradução não pode ser considerada satisfatória em todas as variedades do espanhol, porque o sufixo -ita/o em castelhano é associado frequentemente a uma visão poético-infantil ou lúdica, mesmo eufemística, e pode resultar arcaico. O termo "chiquito" é uma palavra que perdeu a sua recorrência de uso no espanhol peninsular pela presença de "chico" como sinônimo de "menino", de sorte que apenas na Colômbia e na Venezuela “chiquito" conseguiu se lexicalizar (ZULUAGA OSPINA, 1970, p. 27). De fato, no espanhol,

o diminutivo não coincide com tamanho reduzido ou diminuição, mas com valor afetivo-ativo ou emocional (ZULUAGA OSPINA, 1970). Quanto ao uso do grau diminutivo, Guimarães Rosa poderia, em certa medida, ser comparado a Gabriel García Márquez ${ }^{4}$, pois Cem Anos de Solidão conta, no original em espanhol, com cento e setenta e cinco diminutivos (ZULUAGA OSPINA, 1970). Isso nos coloca em face de um problema extralinguístico de tipo i) diatópico, visto que o diminutivo afetivo é muito mais comum na América Latina do que na Península Ibérica; ii) diafásico, pois o diminutivo é próprio do estilo familiar-coloquial (e.g. todito, Nachito); ou iii) diastrático, por ser frequente em grupos sociais populares (e.g. mijita, de verdadita). Se empreendermos uma pesquisa histórica, constataremos que os colonizadores recorriam ao diminutivo com vistas a assinalar a submissão dos grupos étnicos colonizados, pois, ao infantilizá-los, justificavam moralmente a ingerência colonizadora sob os auspícios do discurso paternal. Conforme Ferro (2000, p. 190), "el propietario blanco perpetuaba en los negros su condición de niño, confiriéndoles nombres cristianos a los que ellos agregaban un diminutivo". Guimarães Rosa parece mesmo utilizar o diminutivo como corolário linguístico de um território cuja gente sofreu processo de colonização. A propósito do diminutivo, Montes Giraldo expõe: 
el diminutivo, si bien es usado por personas de todos los ámbitos sociales, predomina especialmente en el habla de las clases menos pudientes. [...] Esto lo podemos explicar por dos motivos: en primer lugar, porque la profusión del diminutivo es un rasgo del habla dialectal en cuanto se opone al habla general [...]; en segundo lugar, el mayor uso del diminutivo en las clases bajas se debe en parte a que las personas pertenecientes a ellas se comportan generalmente con una especie de apocamiento, motivado por un sentimiento de inferioridad hacia los miembros de clases más pudientes (MONTES GIRALDO, 2000, p. 245-246).

Portanto, escolhemos como estratégia de tradução a neutralização ou a variação (visto que mudamos de variante linguística) para a palavra "pequenina”, e por isso decidimos traduzila como pequeña no primeiro caso e diminuta no segundo. A conservação do diminutivo marcaria o caráter infantil ou uma específica variedade "diatópica".

\section{Considerações finais}

O parentesco entre o português e o espanhol constitui, ao mesmo tempo, um fator que facilita e dificulta a tradução interlingual. De um lado, favorece ao não impor, em princípio, desafios que demandem emprego constante de estratégias de tradução oblíqua (como a transposição, a modulação, a equivalência e a adaptação). Diferentemente da tradução entre idiomas muito distintos entre si, a transferência linguística entre línguas com relação parentética se dá mediante emprego mais recorrente das modalidades de tradução direta (tradução literal, empréstimo e decalque). Contudo, a mesma proximidade que faz o espanhol parecer mais acessível ao lusófono e o português ao hispanofalante do que outros idiomas impõe armadilhas que logo esfacelam o otimismo de juízos apressados, haja vista a profusão de falsi amici que traem o aprendiz mais descuidado.

No âmbito da tradução, mesmo o tradutor experimentado se vê, por vezes, em face de opções que provocam indecidibilidade se não houver decisão apriorística quanto ao enfoque adotado - seja a estrangeirização, seja a familiarização, por exemplo. Ao levarmos em consideração as peculiaridades do poema $O$ cágado, bem como da escrita rosiana tout court, optamos por um exercício tradutório cuja primazia repousa no elemento rítmico. Ainda assim, deparamo-nos com diversas situações aporísticas nas quais a escolha entre um ou outro termo encerrava, inequivocamente, alguma perda em favor de determinado ganho. Esse exercício metatextual de tradução, seguida de reflexão sobre a experiência mesma da recriação, restou evidente que a tradução do português para o espanhol, sobretudo de um texto poético como o de Guimarães Rosa, apresenta fatores sintáticos, semânticos e pragmáticos que facilitam o processo tradutório e outros tantos que o dificultam. De todo modo, este trabalho demonstrou 
ser possível traduzir poesia com observância ao texto original quando se adota o ritmo como chave de leitura, tal qual preconizado por Meschonnic, de cuja premissa nos valemos.

\section{REFERÊNCIAS BIBLIOGRÁFICAS}

CANDIDO, Antônio. O homem dos avessos. In: CANDIDO, Antônio. Tese e Antítese: ensaios. São Paulo: T.A. Queiroz, 2002. p. 122.

FERRO, Marc. La colonización: una historia global. México D.F.: Siglo XXI, 2000.

GARCÍA DE LA BANDA, Fernando. Traducción de la poesía y traducción poética. III Encuentros complutenses. Madrid: Universidad Complutense de Madrid, 1993.

HARLAND, Michael. Plotino e Jung na obra de Guimarães Rosa. Revista Colóquio/Letras, n. 46 , p. $28-35,11 / 1978$ e n. 49 , p. $20-33,5 / 1979$.

HURTADO ALBIR, Amparo. Traducción y traductología: introducción a la traductología. Madrid: Catédra, 2011.

JUNQUEIRA, Ivan. A poesia é traduzível? Estudos Avançados, v. 26, n. 76, p. 9-14, 2012.

190 LEONEL, Maria Célia de Moraes. Guimarães Rosa: Magma e gênese da obra. São Paulo: Editora UNESP, 2000.

MESCHONNIC, Henri. Poética do traduzir. Traduzido por: Jerusa Pires Ferreira e Suely Fenerich. São Paulo: Perspectiva, 2010.

MONTES GIRALDO, José Joaquín Otros estudios sobre el español de Colombia. Bogotá: Instituto Caro y Cuervo, 2000.

NORD, Christiane. Texto base-texto meta: Un modelo funcional de análisis pretraslativo. Traduzido e adaptado por: Christiane Nord de Textanalyse und Übersetzen, 2009. Castelló: Servei de Publicacions, 2012.

ROSA, João Guimarães. Grande Sertão: Veredas. In: ROSA, João Guimarães. Ficção

Completa. Volume II. São Paulo: Editora Nova Aguilar, 1994.

ROSA, João Guimarães. Magma. Rio de Janeiro: Nova Fronteira, 1997.

ROSA, João Guimarães. Gran Sertón: Veredas. [Edição ao cuidado de Coral Pérez]. Caracas: Fundación Editorial el perro y la rana, 2008.

TORRES, Mario René Rodríguez. Guimarães Rosa e outros escritores provincianos latino-americanos (Arguedas, Rulfo, Roa Bastos e García Márquez). Dissertação (Mestrado em Letras) - Faculdade de Filosofia, Letras e Ciências Humanas, Universidade de São Paulo, São Paulo, 2009. Disponível em: https://www.teses.usp.br/teses/disponiveis/8/8151/tde-20082009-

154650/publico/MARIO_RENE_RODRIGUEZ_TORRES.pdf. Acesso em: 4 out. 2019. 
ULSH, Jack Lee. From Spanish to Portuguese. Washington, D.C.: Foreign Service Institute, 1971.

VINAY, Jean-Paul.; DARBELNET, Jean. Stylistique comparée du français et de l'anglais: Méthode de traduction. Paris: Didier, 1958.

ZULUAGA OSPINA, Alberto. La función del diminutivo en español. Thesaurus. Tomo XXV, n. 1. Madrid: Centro Virtual Cervantes, 1970.

\footnotetext{
* Raimundo Expedito dos Santos SOUSA - Doutor em Teoria da Literatura e Literatura Comparada (2018) pela Faculdade de Letras da Universidade Federal de Minas Gerais. Mestre com em Estudos Literários (2013) e graduado em Letras (2008) pela Faculdade de Letras da Universidade Federal de São João del-Rei. Professor na Faculdade do Centro Educacional Mineiro. Belo Horizonte, Minas Gerais, Brasil.

Currículo acadêmico: http://lattes.cnpq.br/0070090312079084

ORCID: https://orcid.org/0000-0001-5604-8781

E-mail: raimundo_sousa@terra.com.br

** Hugo Domínguez SILVA - Mestre em Língua e Cultura Italiana (2018) pela Universita Degli Studi di Napoli L'orientale, Itália. Graduado em Tradução e Interpretação (2016) pela Universidad de Vigo, Espanha.

Currículo acadêmico: http://lattes.cnpq.br/7128988434156002

ORCID: https://orcid.org/0000-0002-7086-8863

E-mail: hugodominguezsilva@ hotmail.com

${ }^{1}$ Ênfase adicionada. Doravante, são nossos todos os negritos em transcrições dessa obra, quer no original em português, quer na tradução em espanhol.

${ }^{2}$ Aqui se emprega a estratégia de tradução que Hurtado Albir (2011) denomina "modulação".

${ }^{3}$ Hurtado Albir (2011) chama essa solução ou estratégia de equivalente acuñado.

${ }^{4}$ Torres (2009) se refere aos "escritores provincianos" que foram comparados com Guimarães Rosa, por Antônio Cândido, em várias ocasiões: Gabriel García Márquez, José María Arguedas, Juan Rulfo e Roa Bastos.
} 